\title{
T-tube vs Primary Common Bile Duct Closure
}

\author{
Joshi $M R^{\prime}$, Singh DR' \\ 'Department of surgery, Kathmandu Medical College, Sinamangal, Kathmandu, Nepal
}

\section{ABSTRACT}

Introduction: Closure of the common bile duct over T-tube after exploration is a widely practiced traditional method. However, its use may give rise to many complications. We do primary closure of common bile duct after exploration. Aim of the study is to see the efficacy and safety of the primary closure.

Methods: Study was carried out to compare the results of both the techniques from 2006 to 2009 in the cases proven to have common bile duct stone with or without the features of obstructive jaundice. Post operative hospital stay and morbidities related to both the groups were recorded and analyzed.

Results: There were total 71 cases included in the study. Thirty one in T-tube group and 40 in primary closure group. T-tube was removed in most of the cases after three weeks where as average time of drain removal in primary closure group is $5.79 \pm 1.79$ days. Incidence of retained stone was equal in each group. Major complication in T-tube group is biliary peritonitis in four patients at the time of T-tube removal whereas none of the patient from primary closure group suffered from such major complication.

Conclusions: Primary closure after the common bile duct exploration is safe and it helps to avoid the morbidities related to T-tube.

Keywords: Choledocholithiasis, Primary closure, retained stone, T-tube, Ureterorenoscope.

\section{INTRODUCTION}

Common bile duct (CBD) stones have been managed historically by supraduodenal choledochotomy, stone removal and the duct repair around T-tube. As the incidence of retained stone was more than 10\%, T-tube tract was used for per-cutaneous stone removal postoperatively. ${ }^{1}$ The problems related to T-tube are a longer hospital stay, higher cost of hospitalization ${ }^{2}$ and serious morbidity if the T-tube is dislodged or removed before the tract is developed. So, the T-tube is kept for 3-4 weeks before removal. ${ }^{3}$ The most frequent complication of T-tube removal is bile leakage in $1-19 \%$ of cases. ${ }^{4}$

Primary closure of the CBD was first described by Halstead in $1917 .{ }^{5}$ Mayo, ${ }^{6}$ Kirschner, ${ }^{7}$ Mirrizzi, ${ }^{8}$ Edward and Herrington, ${ }^{9}$ and Herrington et al $^{10}$ are the proponent of the primary closure. Recently, with the availability of per-operative cholangiography, choledochoscopy and

Correspondence:

Dr. Mukund Raj Joshi,

Department of General Surgery

Kathmandu Medical College Teaching Hospital

Baburam Sadak, Sinamangal, Kathmandu, Nepal.

Email: mukundrajioshi@yahoo.com

Phone: 9851047298 
per-operative ultrasonography, incidence of retained stone is very low. So, there is increasing trend towards the primary closure. We have compared the two groups.

\section{METHODS}

A prospective, comparative study carried out at department of general surgery, Kathmandu Medical College during the period 2006 to 2009. Permission of ethical committee and informed consent of patient was taken. We included all the patients who underwent common bile duct exploration for choledocholithiasis. The study is carried out since the time when we started primary closure of the CBD inspite of closing it with T-tube. We have tried to compare the advantage and disadvantages of the procedure during this period with the group of patients who have undergone the conventional method of using T-tube due to various reasons. The patients who had acute severe inflammation, acute obstructive suppurative cholangitis, acute pancreatitis and patients with sand like stones are excluded from the study as these patients need decompression of the CBD so they need T-tube invariably. Primary closure is not done in the cases where the stone clearance is doubtful and excessive instrumentation had been done for dilatation of papilla and stone removal.

The patients included in study were the patients having common bile duct stones larger than $5 \mathrm{~mm}$ and multiple stones detected during ultrasonography as an investigation either for obstructive jaundice or abdominal pain. All patients were reconfirmed for the CBD stone by repeating the ultrasonography at our centre. Some of the cases where the findings are doubtful, patients have undergone Magnetic resonance cholangiopancreatography (MRCP). We have also included the patients who are asymptomatic and unable to pass CBD stones despite of conservative treatment with antispasmodics for one week.

All patients included in study had undergone preoperative investigation complete blood count (CBC), Renal function test (RFT), Liver function test (LFT), Chest X-ray and repeat Ultrasonography before surgery. Informed consent is taken by surgeon himself and surgical resident. Patients who have been planned for primary closure were explained about the surgical plan and procedures, probability of prolonged postoperative bile leak, chance of retained stone and possibility of Endoscopic Sphincterotomy and stenting in postoperative period.

After pre-operative workups, patients were subjected for surgery. Cholecystectomy is done as standard. CBD dissected, incision given in between two stay sutures. Stones are removed. Choledochoscopy was performed by either flexible bronchoscope or semi rigid ureterorenoscope. Once the stone clearance is assured, common bile duct is closed with 4-0 polyglactin with round body needle taking interrupted sutures. Drain is kept in Morrison's pouch. In post operative period, drain is kept till there is bile stained fluid in drain. Once the drain is nil, ultrasonography is done to make sure that there is no collection in and around common bile duct.

In T-tube group, after the stone clearance is assured during surgery, dilatation of the papilla is done in some cases, depending upon the surgeon's choice. Appropriate sized polythene T-tube was used and duct is closed over T-tube. Drain is kept in right sub-hepatic space. Drain is removed once there is no fluid. T-tube is removed after seven days to four weeks. The data collected was compiled and analyzed using statistical package for social sciences (SPSS) version 16 for windows.

\section{RESULTS}

Seventy one patients had undergone open Common bile duct exploration. Forty cases were managed with primary closure whereas in 31 cases common bile duct was closed over T-tube. Majority 49(69.01\%) had multiple stones. Numbers of stones are comparable between two groups and method of choledochoscopy (Ureterorenoscope or bronchoscope) is also comparable. In most of cases, semirigid ureterorenoscope (58\%) was used to visualize and removal of the common bile duct stones.

Out of 31 patients, who had undergone T-tube placement, T-tube was dislodged in three patients, three developed electrolyte disturbances and one suffered from T-tube related biliary colic. Major complication that occurred was post T-tube removal biliary peritonitis in four (12.9\%) (Figure2). Average age of the patient in this age group is $45 \mathrm{yrs}$ and male:female is $1: 2$.

In primary closure group, majority were females, (1:2). Mean age group was 40 (Figure 1). In eight (20\%) patients, there was bile leak from closure site. Most of them leaked for 3-6 days $(80 \%)$. Only three cases had prolonged leak for more than six days. Mean time of drain removal is $5.79 \pm 1.793$ days and mean hospital stay time is $6.76 \pm 1.914$ days. None of them developed biliary peritonitis and none of them required further intervention. Post operative ultrasonography done in all patients before drain removal was normal.

On comparison between two groups, numbers of stones, co-morbid medical conditions and method of stone clearance are comparable. There is no significant difference regarding minor complications and retained stones. But there is obvious advantage in primary closure group over T-tube group in relation to prolonged 
T-tube placement and T-tube related complications like electrolyte disturbances, T-tube colic and post T-tube removal bile leakage (Table 1 ).

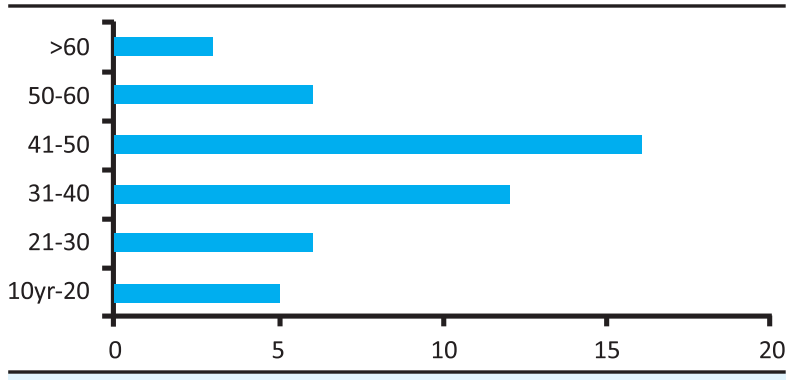

Figure 1. Different age group (primary closure).

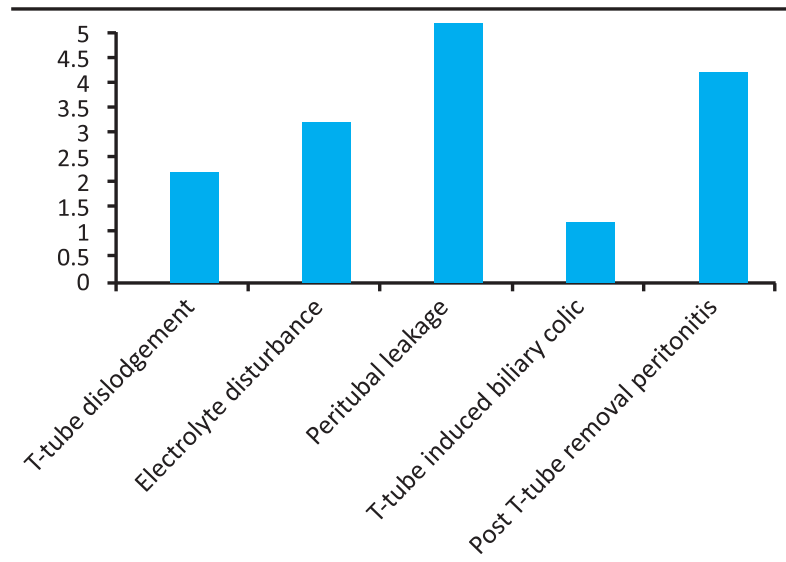

Figure 1. Number of cases in different $\mathrm{T}$-tube related complications.

Table 1. Comparison between two groups for biliary peritonitis in post op period.

\begin{tabular}{|c|c|c|c|}
\hline & \multicolumn{2}{|c|}{ Biliary peritonitis. } & Total. \\
\hline Groups & no & Yes & \\
\hline Primary closure & 40 & 0 & 40 \\
\hline T-tube closure & 27 & 4 & 31 \\
\hline Total & 67 & 4 & 71 \\
\hline
\end{tabular}

$P=<0.05$.

\section{DISCUSSION}

When the common bile duct surgery was started by Halsted in 1921, it was the primary closure of the duct. This technique was continued for many years. Later due to high incidence of retained stones in common bile duct, T-tube was used so that different technique can be applied for removal of retained stones through the matured T-tube tract post-operatively. Another rationale of using T-tube is with the belief that the T-tube helps to decompress the common bile duct and prevents the biliary leak due to post-traumatic edema of sphincter in post-operative period. ${ }^{11}$ But the use of T-tube is not without complications. It is associated with peritubal leakage, excess bile drainage and electrolyte imbalance, peritubal cellulitis, sepsis, necrotizing fasciitis, post T-tube removal bile leakage etc. ${ }^{8,12-14}$ Hence, recently the invariable use of T-tube is being challenged. The three randomized controlled trials by De-Roover et $\mathrm{al}^{15}$ Sheen-Chen et $\mathrm{al}^{16}$ and Williams et $\mathrm{al}^{17}$ found no difference in outcome between primary closure and T-tube groups except the longer hospital stay in T-tube group.

Initially, in our institution, T-tube closure was considered mandatory and T-tube was used invariably in every case of common bile duct exploration. Usually the T-tube clamping is started after seventh post operative day and the patient is discharged to be followed up in outpatient department. Patients would remain in hospital for longer period and patient had to carry the T-tube for more than three weeks giving rise to prolonged morbidity of around one month in T-tube group. Complications in the patients with T-tube had been analyzed. Patients with minor complications like electrolyte disturbances were managed with ORS supplement. In two patients, T-tube was dislodged causing the prolonged bile leakage in drain. None of these suffered the peritonitis. They were managed conservatively. One patient had suffered recurrent colicky pain in post-operative period although the T-tube cholangiogram was normal. T-tube was removed on $12^{\text {th }}$ day and there was no more pain. Most probably the size of T-tube (14fr) was larger for small sized common bile duct. The most difficult complication to handle had been post T-tube removal bile leakage. Out of three patients who had this problem, one had to stay for 1 month and two others stayed around 20 days in hospital for repeated aspiration of bile although none of them required the re-laparotomy or ERCP and stenting. These results are comparable with other similar observations. T-tube has been found to be associated with many complications by many authors. Marwah $\mathrm{S}$ has observed the increased biliary infection and wound infection associated with T-tube. ${ }^{14}$ Moreux suggests the external loss of bile through T-tube may lead slow wound healing, anorexia and constipation (Post-choledochotomy acidotic syndrome). ${ }^{18}$ Similarly, Gillant and Reinhoff proposed that the incidence of recurring stones would be greater in choledochotomy followed by T-tube drainage as T-tube acts as foreign body around which bile pigments and bile salts may precipitate. ${ }^{19-20}$

In primary closure group, although the drain was kept in every case, bile was seen in drain tube only in eight patients out of total 40 patients. Most of the patients (approx.80\%) had drain tube in situ for 3-6 days. In our series, Mean time of drain removal is $5.79 \pm 1.793$ days and mean hospital stay time is $6.76 \pm 1.914$ days. Three patients had biliary leakage for more than six days but the drain stopped uneventfully with conservative treatment. None of the patient suffered the drain block 
and other major complications and none of them required any further intervention like re-exploration, ERCP and stenting. The result of the present study are quite comparable with similar other studies. Gigot reported median hospital stays of 7.7 days with and 4.7 days without biliary drainage. ${ }^{21}$ Slight longer hospital stay is seen in our series because we tend to keep patients for slightly longer period as it is our early experience.

In overall, In T-tube group, there is longer hospital stay and prolonged morbidity related to T-tube in situ for more than three weeks whereas the patients of primary closure group are ready for daily household work within 10-14 days. This has shown the great benefit for the patient in primary closure group.

Whatever the technique used for common bile duct exploration, external biliary drainage, either transcystic or via T-tube carries a specific morbidity ranging from 0 to $6.3 \%$ in series of open Common bile duct exploration. ${ }^{22}$ It has been shown that CBD exploration may be performed safely without biliary drainage even in cases of cholangitis. ${ }^{23}$

In our observation, we have found that bile leakage occurs in cases where the common bile duct is thin, non inflamed and non edematous. Most of the cases of common bile duct stone have thick edematous two layered bile duct which is less likely to leak through the needle prick site. Residual stone in our series has been nil despite of more than six month observation in most of the cases. Direct choledochoscopy had been used in all cases and primary closure was done only when the Common bile duct was considered to be stone free by all the operating team members watching choledocoscopy in monitor. In this study we have excluded the cases where there were multiple uncountable stones including in intrahepatic ducts. This might be the cause of the low residual stone incidence. For the primary closure of the common bile duct, stone free common bile duct must be ensured. ${ }^{24}$ Although none of the method is $100 \%$, direct visualization of the common bile duct by cholodochoscopy is found to be the most accurate. ${ }^{25-27}$ In our institute we did not have the proper choledochoscope but for this purpose we had been using the flexible bronchoscope until the author started using semirigid ureterorenoscope. Semirigid ureterorenoscope has the added advantage of using the stone holding forceps and intracorporeal pneumatic lithotripsy which we had to use in few occasions.

\section{CONCLUSIONS}

Primary closure of the common bile duct is safe and effective method and it helps to reduce the morbidity related to $\mathrm{T}$-tube use. It reduces the hospital stay and overall cost and it can be done in most of the cases.

\section{ACKNOWLEDGEMENT}

We would like to thank the faculty and the staffs of department of general surgery, department of Anesthesia and operation theatre for their help and support during the study.

\section{REFERENCES}

1. Ellis H. Choledocholithiasis. Maingot's Abdominal Opertions. NOrwalkm CY: Appleton-Century-Crofts, 1985. p. 1883-907.

2. Chen SS, Chou FF. Choledochotomy for biliary lithiasis: Is routine T-tube drainage necessary: Acta Chir Scand. 1990;156:387-90.

3. Seale AK, Ledet WP Jr. Minicholecystectomy: a safe, cost-effective day surgery procedure. Arch Surg. 1999 Mar;134(3):308-10.

4. Wills VL, Gibson K, Karihaloot C, Jorgensen JO. Complications of biliary T-tubes after choledochotomy. ANZ J Surg. 2002 Mar;72(3):177-80.

5. Halstead WS. Surgical Papers. Baltimore; Md. John Hopkins University Press: 1924. p. 427-72. (Vol 2)

6. Mayo WI. An address on the surgery of the hepatic and common bile ducts. Lancet; 1923;1:1299-1302.

7. Krischner $\mathrm{M}$, ed. Operations on the gall bladder and the bile passage. In: radvin IS, trans. Vol 2. Abdomen and Rectum. In: Operative Surgery. Philadelphia, PA: JB Lippincott; 1933. p. 460-517.

8. Mirrizzi PL. Primary suture of the common bile duct in choledocholithiasis. Arch Surg. 1942;44:44-54.
9. Edwards LW, Herrington JL Jr. Closure of the common bile duct following its exploration. Am Surg. 1953;137:89.

10. Herrington JL Jr, Dawson RE, Edwards WH, Edwards LW Further consideration in the evaluation of primary closure of the common bile duct following its exploration. Am Surg. $1957 ; 145 ; 153-61$.

11. Catton JA, Lobo DN. The use of drains in gastrointestinal Surgery. Recent Advances in Surgery 31: Taylor I, Johnson C 2009. p. 13-26.

12. Gharaibeh KIA, Heiss HA. Biliary leakage following T-tube removal. Int Surg. 2000;85:57-63.

13. Sawyers JL, Herrington JL, Edwards WH. Primary closure of the Common Bule Duct. Am J Surg. 1965;109;107-12.

14. Marwah S, Singh I, Godara R, Sen J, Marwah N, Karwasra RD. Evaluation of primary duct closure Vs T-tube drainage following choledochotomy. Indian J Gastroenterol. 2004.23:227-8

15. De Roover D, Vanderbeken M, Gerard Y. Choledochotomy: primary closure versus T-tube. A prospective trial. Acta Chir Belg. 1989;89:320-4. 
16. Schen-Chen SM, Chou FF. Choledochotomy for biliary lithiasis: Is routine T-tube drainage necessary? A prospective controlled trial. Acta Chir Scand. 1990;156;387-90

17. Williams JA, Treacy PJ, Sidey P, Worthley CS, Towensent NC, Russel EA. Primary duct closure versus T-tube drainage following exploration of the common bile duct. Aust NZ J surg. 1994;64:823-26.

18. Moreaux J. Traditional surgical management of common bile duct stones: a retrospective study during a 20 yaear experience. Am J Surg. 1995;169;220-6.

19. Gillant DA, May RE, Kennedy R, Longstaff AJ. Complication of T-tube drainage of the common bile duct Ann R Coll Surg. 1985;67:170-1.

20. Reinhoff WF. Primary closure of common bile duct. Ann Surg. 1960;151:255-61.

21. Gigot JF, Navez B, Etienne J, Cambier E, Jadoul P, Guiot P, et al. A stratified intraoperative surgical strategy is mandatory during laparoscopic common bile duct exploration for common bile duct stones. Lessons and limits from an initial experience of 92 patients. Surg Endosc. 1997 Jul;11(7):722-8.
22. Cuschieri A, Croce E, Faggioni A, Jakimowicz J, Lacy A, Lezoche E, et al. EAES ductal stone study. Preliminary findings of multi-center prospective randomized trial comparing two-stage vs single-stage management. Surg Endosc. 1996 Dec;10(12):1130-5.

23. Sheen-chen S, Chou FF (1990). Choledochotomy for biliary lithiasis: is routine T-tube drainage necessary? A prospective controlled trial. Actoa Chir Scand. 156:387-90.

24. Zhiyuan $\mathrm{Tu}$, Jiadong Li, Hailin Xin, Qin Zhu, Tongnian Cai. Primary cholodochorrhaphy agrer common bile duct exploration. Digestive surgery. 1999;16:137-9.

25. Menzies D, Motson RW. Operative common bile duct imaging by operative cholangiography and flexible choledochoscopy. Br J Surg. 1992 Aug;79(8):815-7.

26. Wheeler BR, Anigian G, Stephens G, Larson GM Choledochoscopy and common bile duct exploration. Am Surg. 1990 Mar;56(3):182-4.

27. Bauer JJ, Salky BA, Gelernt IM, Kreel I. Experience with the Flexible Fiberoptic Choledochoscope. Ann. Surg. 1991 Aug. 